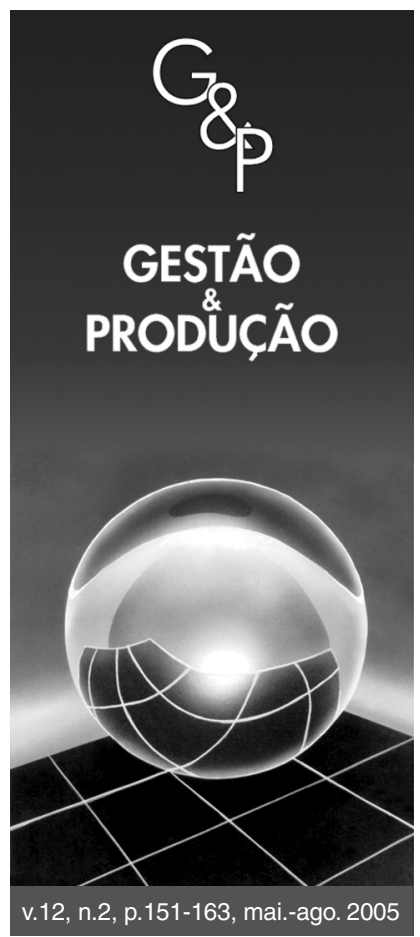

\title{
MODELO DE REDES SIMULTÂNEAS PARA AVALIAÇÃO COMPETITIVA DE REDES DE EMPRESAS
}

\author{
José Paulo Alves Fusco \\ Departamento de Engenharia de Produção, \\ Universidade Paulista, Campus Indianópolis, \\ Rua Dr. Bacelar, 1212, CEP 04026-002, 4ªndar, Vila Clementino, São Paulo, SP, \\ e-mail: jpafusco@uol.com.br

\section{Gressiqueli Regina Chiachio Buosi} \\ Rosangela Carmona Rubiato \\ Programa de Mestrado do Departamento de Engenharia de Produção, \\ Universidade Paulista, Campus Indianópolis, \\ e-mail: gressi@ bef.com.br, rosangela@ rubiatto.com.br
}

Resumo

A formação e desenvolvimento das redes e da teoria das Cadeias de Fornecimento têm ganhado maior relevância recentemente. Ao longo do tempo, a Administração de Operações tem evoluído sob uma perspectiva holística, abrangendo também questões como rede de fornecimentos, governança, relações de confiança e outras. No mesmo raciocínio, muito tem sido feito pelos pesquisadores, primordialmente com relação a aspectos de competitividade, produzindo uma grande variedade de modelos e tipologia de avaliação. Contudo, o propósito geral tem sido explicar a dinâmica de um negócio e como as diretrizes competitivas de firmas devem ser mudadas a fim de obterem sucesso. Este artigo tem por objetivo apresentar uma abordagem metodológica alternativa, baseada em três principais dimensões de redes simultâneas, ou seja, rede física, de valor e de negócios, para subsidiar a avaliação da competitividade de redes e cadeias de fornecimentos de maneira geral. O artigo apresenta comentários e algumas conclusões preliminares, obtidas em um projeto de pesquisa, ainda em andamento, que envolve a utilização do modelo aqui proposto no setor de papel e celulose.

Palavras-chave: cadeias de fornecimentos, redes simultâneas, avaliação de competitividade.

\section{Introdução}

Atualmente, no ambiente econômico dinâmico de alta competição e globalização, as empresas buscam aproveitar todas as possibilidades para vender seus produtos, principalmente explorando outros mercados. A competição acontece entre redes de cooperação e não entre empresas isoladas. Assim, torna-se necessário considerar as questões típicas relacionadas à coordenação e integração de cada ator envolvido em cada processo de negócios, além do surgimento da competição baseada no tempo (time-based competition).

Adicionalmente, em alguns setores industriais, a opção por um determinado papel estratégico para balizar as operações de uma empresa, normalmente envolve altos níveis de investimentos em termos de equipamentos, instalações, aquisição de tecnologia e desenvolvimento de mão de obra. Tais fatores podem significar um forte com- prometimento geográfico e local, relacionados a aspectos que podem, também, ser difíceis de mudar a curto prazo. Quando mudanças ocorrem no cenário competitivo, torna-se uma tarefa árdua reformular o perfil da estratégia de operações e mudar a natureza de alianças estabelecidas, algumas de longa data e com grande envolvimento entre os parceiros. Assim, é necessário desenvolver uma abordagem para equacionar a natureza dinâmica das atividades e seus reflexos nas correspondentes dimensões competitivas, para se obter uma avaliação competitiva válida de uma rede de empresas com relação a um negócio específico. O presente artigo tem por objetivo principal propor uma abordagem metodológica alternativa às já existentes, baseada no conceito de redes simultâneas (física, de valor, de negócio) para subsidiar a avaliação da competitividade de redes de empresas e cadeias de forne- 
cimento (CS) de modo geral. Para ilustrar o modelo proposto, foi realizada uma pesquisa qualitativa exploratória buscando entender a própria natureza dos relacionamentos entre os parceiros. Os dados e os resultados obtidos sugerem que as atividades da rede de negócios desempenham um papel chave e representam a base para se obter as condições e requisitos reais exigidos pelo mercado.

\section{Redes simultâneas}

A existência ou não de uma rede, obviamente independe de sua definição teórica ou proposição de modelos de avaliação pela academia. Na Administração, via de regra, a realidade do fato precede sua contextualização teórica, ao contrário do que normalmente ocorre nas ciências exatas. No entanto, um fato também depende da compreensão dos seus pressupostos para poder compor uma determinada visão de mundo ou experiência, que vai , por sua vez, servir de base para que outros fatos aconteçam de uma forma mais evoluída no futuro.

$\mathrm{O}$ assunto rede de empresas tem seguido um caminho semelhante até atingir as dimensões de análise que estão presentes na vasta literatura existente a respeito. Não obstante a quantidade de autores, alguns parecem ter maior interesse devido ao tratamento multidimensional que conferem às suas contribuições. Benko (1996), por exemplo, define rede como sendo "a dimensão espacial de uma forma de regulação entre unidades produtivas". Prosseguindo, o autor afirma que "governança corresponde ao modo de regulação dessas relações". Sacomano Neto (2004), por sua vez, explora o potencial de se utilizar a organização em rede, em si, como uma forma de governança. Neste caso, rede poderia ser interpretada como uma alternativa de organização para se manter o sistema de operações sob controle. Paulillo (2000) sugere o conceito de redes de cooperação, com o objetivo de prover o conjunto dos atores de condições agregadas superiores de competitividade e, neste caso, rede seria uma alternativa de organização para se otimizar as operações (eficiência) ou atender melhor a necessidades ditadas pelo contexto concorrencial (eficácia). Van Waarden (1992) afirma que "em muitas ocasiões, um grupo de interesses apresenta poder de aglutinação suficiente para representar uma determinada categoria, mas não consegue legitimidade, porque não lhe é atribuído reconhecimento ou reputação pelos demais agentes privados ou não lhe é atribuído 'status' publico pelo estado". Neste caso, a organização em redes pode ser interpretada como uma forma para se adquirir maior representatividade. A abordagem aqui sugerida pretende cobrir alguns aspectos relevantes, mas sem visar à obtenção de um modelo completo, mesmo porque os próprios conceitos mudam com o tempo e novas dimensões de análise vão surgindo todos os dias.

\subsection{Rede física}

À medida que o desenvolvimento da tecnologia se acelera, torna-se cada vez mais difícil às empresas manterem as condições adequadas dos desenvolvimentos tecnológicos e de processos nas áreas em que concorrem, de modo a manterem atualizados os produtos e serviços que oferecem ao mercado. Isso, de certa forma, tem imposto uma necessidade de maior concentração em suas competências essenciais (Prahalad e Hammel, 1990), delegando a terceiros parcelas cada vez mais substanciais, não só da produção de partes de seus produtos e serviços, mas também do próprio desenvolvimento destas partes. Tais movimentos por parte das empresas têm aumentado bastante a quantidade e a intensidade de trocas nas interfaces da CS em que se encontram, além de se tornarem mais complexas.

Para Vollmann e Cordon (1996), a visão tradicional de competição é baseada em unidades de negócios competindo entre si pelo mesmo mercado. No entanto, à medida que foram surgindo novas formas de alianças entre empresas participantes da cadeia, têm ficado cada vez mais difusas as fronteiras das unidades de negócios, praticamente definindo uma nova visão de competição, mas agora entre CS. Não basta mais melhorar internamente os processos de uma empresa para elevar sua competitividade, é preciso considerar melhorias que privilegiem o desempenho da sua cadeia produtiva (Christopher, 1992; Poirier e Reiter, 1996; Vollmann e Cordon, 1996). A gestão das relações entre os parceiros da CS passou, portanto, a ganhar muito mais atenção gerencial (Corrêa, 2003). Cada vez mais, as empresas têm focalizado um conjunto bem definido e restrito de tarefas, comprando materiais e serviços de fornecedores que têm esta atividade como sua principal especialidade. Portanto, a partir daquela época, os autores definiram que o novo paradigma competitivo passou a envolver a CS e, como consequiência, o sucesso de qualquer empresa passou a ser dependente do grau de acerto desta, na administração de suas relações internamente às cadeias das quais participa.

Segundo Vollmann et al. (1996), a CS pode ser vista como um canal de fluxo de informações em que são processadas matérias-primas, transformando estas em bens ou serviços que são entregues aos consumidores finais, enfatizando o fluxo físico de materiais e a exploração dos relacionamentos entre os elos da rede de fornecimentos, de forma a reduzir custos ou agregar valor na ótica dos clientes finais. Outros autores (Vollmann et al., 1996; Slack et al., 1998; Spekman et al., 1998) resumem os objetivos da gestão de uma CS em maximizar as sinergias entre todas as partes da cadeia com o propósito de servir o consumidor final mais efetivamente, seja reduzindo custo ou acrescentando valor e gerenciando a cadeia efetiva e eficientemente, adotando uma perspectiva holística de 
modo a poder aproveitar oportunidades adicionais para melhorias.

A "rede física" é, de fato, aquela que faz os negócios acontecerem concretamente, ou seja, movimenta insumos e matérias-primas de fornecedores para as plantas produtivas, produz fisicamente os bens e serviços, movimenta internamente os materiais em processo, armazena e distribui os resultados do processo entre os diversos clientes. Tais atividades devem ser consideradas no âmbito de todas as empresas que formam a rede física visando, sobretudo, manter a alimentação do sistema produtivo de forma a atender às necessidades mais pragmáticas e que dependem de procedimentos físicos para acontecer. Desse modo, empresas que fazem parte da rede física desempenham atividades como viabilizar a obtenção física (produzindo ou adquirindo de terceiros) de produtos que permitam satisfazer as necessidades definidas pelos clientes; implementar alternativas (ou processos) para obtenção das condições que permitam atender (via P/S) às necessidades que os clientes consideram importantes; determinar qual empresa deverá desempenhar quais atividades dentro do sistema físico; medir o grau de obtenção das características físicas, que determinam os valores considerados vitais pelos clientes; operacionalizar o fluxo físico de bens ou linhas de fluxo de serviços entre os participantes da rede de criação de valor e entre estes e o mercado atendido; medir e manter sob controle as variáveis de fluxo; e atender fisicamente ao programa de pedidos.

\subsection{Rede de valor}

A "rede de valor" representa o conjunto de caminhos para obter as condições objetivas que permitam atender às necessidades do cliente. A definição dos principais objetivos a serem atingidos pelas firmas dentro da rede representa também uma parte importante, para entender quais são os processos realmente críticos e espalhar estas informações ao longo do grupo de relações. As pressões competitivas crescentes, que caracterizam muitos setores, estão forçando as companhias a adotarem uma perspectiva dos seus consumidores finais numa tentativa de entender o que eles consideram ser os elementos chave num sistema de fornecimentos e, assim, determinar o valor recebido (Parolini, 1999). Para permitir que seja proposta essa nova abordagem, é necessária a sugestão de um novo modelo (a rede de valor), que assuma os sistemas de criação de valor como um objeto fundamental de investigação e suas atividades como unidades básicas de análise. O primeiro pesquisador a explorar as tarefas e os papéis dentro de um processo mais amplo de entrega e satisfação ao consumidor foi Porter (1985) com o conceito de cadeia de valor $(\mathrm{CV})$. A CV identifica as ligações e interdependências entre (e por meio) de fornecedores, compradores, intermediários e usuários finais. Seu benefício primário é prover um contexto de análise que permita examinar essas ligações e identificar o "valor" que é (ou pode vir a ser) criado para os consumidores, e, com isso, criar vantagem competitiva para a companhia. O "valor" pode tomar a forma de um preço menor, quando da venda de um produto diferenciado aos clientes de uma empresa, ou ainda pode tomar a forma de um dado benefício único (ou especial) que justifique um aumento de preço. O argumento de Porter (1985) é que o conceito de CV pode ser usado para identificar e entender as fontes específicas de vantagem competitiva e como elas se relacionam para criar valor adicionado para os consumidores. Os negócios usualmente se referem a "valor ao consumidor" e "valor adicionado" sem prover definições correspondentes ou entendimento, do que é valor para o consumidor. Para isso, é necessária uma visão detalhada do ponto de vista da estratégia de logística. Assim, valor pode ser a qualidade, a exclusividade, a conveniência ou a resposta possível do serviço (valor intrínseco), em que o denominador comum é o custo para o consumidor, devendo, o custo total para o consumidor, considerar o custo do produto mais os custos incorridos para adquirir o produto (num nível mínimo). Entretanto, os custos não dão uma visão total. Estes devem ser considerados junto com os benefícios de valor que estão disponíveis no pacote total (produtos mais os serviços), antes que o custo total para o consumidor possa ser derivado (Gattorna e Walters, 1996), sugerindo que há valor nos serviços providos por um fornecedor que aumenta a habilidade para servir seus próprios consumidores, levando a uma interessante visão sobre como a entrega de valor pode ser afetada. Gattorna e Walters (1996) sugerem um sistema de "entrega de valor" que estende a noção da cadeia de valor pela inclusão das expectativas dos consumidores para ambos, produto e serviço, introduzindo segmentação, e enfatizando o papel do "valor" no conceito de cadeia de valor. Parolini (1999) propõe que a perspectiva de uma análise estratégica necessita de uma visão mais ampla das companhias individuais para os Sistemas de Criação de Valor (SCV), e, com isso, uma definição detalhada dos SCVs, como em que grau tais sistemas podem ser definidos como sendo uma série de atividades que criam valor, mas sob a ótica dos consumidores; o grau em que essas atividades são realizadas usando-se uma série de recursos humanos, tangíveis e intangíveis; como elas estão ligadas a fluxos de materiais, informação, recursos financeiros e relacionamento influentes; em qual medida os consumidores finais não somente recebem e consomem o valor criado, mas também participam das atividades de criação de valor; em qual medida tais atividades podem ser governadas pelo mercado, por uma hierarquia ou alguma forma intermediária de coordenação (redes de empresas); qual a ocorrência de vários atores econômicos participando de um único SCV (empresas, famílias, enti- 
dades públicas, entre outras) por tomar responsabilidade de uma ou mais atividades; e em qual medida um dado ator econômico pode participar em mais de um SCV. Objetivando analisar os SCVs, deve-se definir exatamente qual o significado para valor, os diferentes significados que a palavra pode ter e, em particular, o que significa valor ao consumidor. Uma melhor explicação sobre o termo pode ser atingida pela exploração das distinções feitas por Bowman e Ambrosini (2000), entre valor de uso e valor de troca.

$\mathrm{O}$ valor de uso refere-se às qualidades específicas do produto percebidas pelos consumidores em relação às suas necessidades (a aceleração e o estilo de um carro). Dessa forma os julgamentos sobre o valor de uso são subjetivos, eles pertencem ao consumidor individual. $\mathrm{O}$ valor de uso é percebido pelo consumidor. $\mathrm{O}$ valor de troca é o preço, é a quantia monetária adquirida num determinado ponto no tempo, quando ocorre a troca por um bem. Assim, o valor de troca é realizado quando a venda é feita e as vendas são realizadas quando os consumidores vêem que um produto confere mais valor ao consumidor que outras possíveis alternativas. Assim, as firmas criam valor percebido de uso e, por meio da venda de produtos, o valor de troca é realizado. Somente na rara instância do fornecedor monopolista, o qual é conhecedor da avaliação dos consumidores, que pode discriminar por preço, será o preço que o consumidor está disposto a pagar igual ao preço que, efetivamente, o consumidor paga. Este preço é conhecido como valor monetário total. Nas outras circunstâncias, o preço pago será menor do que o valor monetário total percebido pelo consumidor. A diferença entre a avaliação do produto pelo consumidor, e o preço pago é o "excedente do consumidor". Ou seja, o preço que se está preparado para pagar é "o preço mais o excedente do consumidor".

Para Parolini (1999), o excedente do consumidor (valor absoluto líquido) deriva de uma combinação de um número diferente de elementos. Um meio de classificar esses elementos é com base em sua natureza como sendo: tangíveis; intangíveis; serviços; e econômicos. Os elementos tangíveis incluem a qualidade intrínseca do produto principal (a qual pode ser avaliada em termos da qualidade do material usado, sua durabilidade, características funcionais, dentre outros), sua aparência estética e a possibilidade de receber acessórios ou produtos complementares. Uma das vantagens da perspectiva da rede de valor está no fato desta levar em consideração as atividades que concorrem para tornar uma oferta mais atrativa ou disponível para o consumidor. Isso significa incorporar todas as atividades que incluem produção de bens complementares ou acessórios, mesmo que esses estejam além do controle da empresa que está fazendo a análise. Elementos intangíveis podem incluir outros subelementos, tal como a presença de prestígio associado ao uso de um dado produto, o grau de segurança atribuído a este produto e se ele leva a assinatura de um famoso designer ou estilista. A presença de uma marca forte é usualmente relacionada com a relevância de elementos intangíveis, além de sugerir que constitui um erro considerar a marca como um elemento intangível por ela mesma. Não é a presença de uma marca bem conhecida que constitui o elemento de valor para o comprador, mas o prestígio ou senso de segurança que os consumidores tendem a associar a uma marca e ao produto.

Quanto aos serviços, o progressivo enriquecimento e articulação da oferta de bens em economias avançadas estão tornando difícil distinguir entre as empresas de manufatura e as de serviço. Esse tipo de evolução está começando a afetar um grande número de indústrias, incluindo aquelas que oferecem commodities, porque a oferta de um serviço pode ser a única forma na qual esse tipo de sistema competitivo pode distinguir-se de outros. Movendo-se de companhias para SCV, se torna praticamente impossível distinguir aqueles que ofertam bens dos que ofertam serviços, porque por definição os SCVs incluem atividades envolvidas na transformação física, assim como, atividades responsáveis pela sua distribuição, instalação, entre outras.

No que tange aos elementos econômicos, estes podem ser divididos em dois grupos: o preço de compra do produto, e todos os outros elementos econômicos que incluem os tempos e métodos de pagamento, a amplitude e duração de quaisquer garantias, o custo de produtos complementares e acessórios, a possibilidade de obter descontos ou outras vantagens em relação à aquisição de outras unidades do bem ou de outros bens. O preço de um produto deve estar claramente separado de todos os outros elementos econômicos, porque ele reflete a síntese de todos os fatores, afetando o processo envolvido em uma dada troca, e compradores tendem a julgar se um preço é justo pela comparação com todos os outros elementos de valor absoluto.

\subsection{Rede de negócios}

A expansão do domínio das redes interfirmas provê recursos da rede, que permitem um maior entendimento das múltiplas avenidas, nas quais as empresas podem obter recursos de seu contexto social, desde que estejam inseridas em muitas redes interfirmas, incluindo algumas que podem prover acesso a capital financeiro e tecnológico. Gulati (1999) já chamava a atenção para o fato de que uma extensão desse estudo poderia considerar as implicações da participação em múltiplas redes com o conseqüiente impacto no comportamento e performance. Algumas possíveis redes incluem board interlocks, laços com bancos de investimentos, participações em associações profissionais, e participação em consórcios patrocinados pelo governo de pesquisa e desenvolvimento. 
A remoção de barreiras internacionais ao comércio, observada nos últimos anos, tornou os mercados globais mais acessíveis, e as novas tecnologias de informação facilitaram a entrada de pequenas e médias empresas em mercados antes inexplorados. A informação rápida sobre oportunidades de negócios internacionais torna-se um recurso superior, e a informação baseada nas redes está permitindo ajudar pequenas e médias empresas a comunicarem-se sobre necessidades e oportunidades de negócios, expandirem seus mercados, compartilharem seus recursos, conhecimento e experiência. Desde o final da década de 90, descobriu-se uma tendência definida no desenvolvimento de "rede de negócios" como uma das estratégias chave para que as companhias, de pequeno, médio ou grande porte, sejam competitivas internacionalmente. A rede de negócios consiste de empresas que tem um papel chave na viabilização das condições e requerimentos necessários para os consumidores de um mercado atendido. Os atores dentro de uma rede de negócios são responsáveis por realizar negociações comerciais e colocar os bens próximos dos consumidores. Em outras palavras, uma rede de negócios é um grupo de negócios que coopera e colabora na procura de novas oportunidades de negócios. Envolve cooperação entre as empresas para empreender projetos - e também a colaboração para alcançar os objetivos que cada uma das empresas não pode alcançar independentemente. As redes não são um novo conceito no mundo de negócios. De fato, desde que surgiram negócios tentando ter lucro, houve esforços cooperativos entre firmas para desenvolver produtos em conjunto, compartilhar suas especialidades, proporcionar apoio valioso e serviços uns aos outros. O que é novo, entretanto, são algumas ferramentas que podem ser utilizadas para projetar e implementar uma rede de negócios. Há muitas razões para que companhias unam forças numa rede de negócios: alcançar vantagens de escala, escopo e velocidade; aumentar sua competitividade em mercados tanto domésticos como internacionais; estimular novas oportunidades de negócios; aumentar exportações; formar novas bases de capitais; criar novos negócios; e reduzir custos.

\subsubsection{As características de uma rede de negócios}

A rede se forma, basicamente, porque os membros necessitam implementar soluções para enfrentar desafios compartilhados de negócios, ou ainda para poder aproveitar oportunidades. Uma vez formada, o crescimento de uma rede dependerá de como encontra as necessidades de negócios de seus membros, e sobre seu compromisso com a aliança a longo prazo. A rede é colaboradora, flexível e não hierárquica, com membros que compartilham decisões de fazer, projetar e implementar estratégias. A rede pode variar em tamanho, objetivo (de acordo com as necessidades dos membros) e estrutura (formal ou informal). Alguns projetos comumente empreendidos por rede de negócios são os projetos de entrada que incluem a compra em conjunto; treinamento de pessoal; financiamento em conjunto; $\mathrm{P} \& \mathrm{D}$; compartimento de recursos, habilidades e informação; identificação de oportunidades de mercado ou de subcontratantes e fornecedores. Os projetos de produção incluem inovação e design; comercialização de novos produtos ou serviços; substituição de importação; marketing; exportação; e solução de problemas.

Alianças estratégicas tornam-se uma alternativa de escolha para pequenas e médias empresas que buscam aumentar vendas para penetrar em mercados estrangeiros, mas não têm o conhecimento de exportação, capacidade financeira nem fôlego de produto para empreender esta iniciativa em suas alianças de negócios. Atividades elegíveis incluem reuniões de estabelecimento de rede, atividades de desenvolvimento em tais áreas como identificação de mercado de exportação, desenvolvimento de produto/ serviço, transporte, treinamento, e atividades de avaliação. Estas atividades de mercado devem contribuir para o crescimento de negócios, diversificação e exportações.

\section{A abordagem de redes simultâneas}

O modelo sugerido pretende categorizar e apresentar uma abordagem metodológica, baseada nos três principais tipos de "redes simultâneas", sendo a física, de valor e de negócios, para analisar de modo crítico as estratégias de CS distintas, envolvendo as condições de competitividade nos diferentes tipos de negócio a serem explorados. O modelo abrange contribuições de autores, abordando assuntos como "redes robustas" (Fusco e Spring, 2003), “papéis das fábricas" (Ferdows, 1997), "localização das firmas" (Schmenner, 1979), "rede de valor" (Parolini, 1999), "rede de fluxo do valor" (Hines et al., 2000), "redes estratégicas" (Jarillo, 1998), "logística e a empresa estendida" (Boyson et al., 1999), "gerenciando a CS" (Gattorna e Walters, 1996), "compras estratégicas e gerenciamento de CS" (Saunders 1997) e outros. O conceito da Unidade Estratégica de Negócios pode ser um elemento adicional porque representa a primeira fase de análise a ser feita previamente, bem como o conceito de "trust e alianças interfirmas" (Nooteboom, 1999) entre parceiros e também governança, sendo importante considerar a eficácia como uma parte de um possível conjunto de critérios de desempenho. Assim como as considerações do modelo teórico de porte médio (Le Galès, 1995) das transformações dos modos de governança e dos setores econômicos e organizacionais, e sua complexidade e diversidade. Para Marsh e Olsen (1993), os resultados de um processo de interação estratégica ocorrem em função das restrições impostas pelas regras, pela distribuição dos interesses entre os atores e da distribuição dos recursos de poder. 
Williamson $(1985,1991)$ afirma que para haver governança devem existir três fatores: o grau de completude do contrato, a possibilidade de não cumprimento de promessas e o grau de identificação entre as partes. Há que se notar que, na abordagem proposta, os próprios assuntos considerados têm implicações profundas uns com os outros. Desse modo, quando se opta por um determinado papel estratégico a ser desempenhado por uma planta ou uma rede, necessariamente está se optando por um determinado nível de custo de transação entre os atores. Nos casos de elevada especificidade dos ativos envolvidos, considerando-se as definições de Williamson (1985) e Paulillo (2000), por exemplo, torna-se necessário trabalhar de uma forma mais profunda a questões da governança do relacionamento e da confiança entre os parceiros. Em casos de alta especificidade de ativos, é desejável que haja um horizonte previsível e adequado para continuidade da transação. De qualquer modo, é importante verificar que quanto maior a especificidade, maiores deverão ser os riscos e problemas de adaptação, quando de um eventual rompimento de contrato. A estrutura de governança deve, portanto, ser modelada para impedir eventuais condutas oportunistas de alguma das partes envolvidas em uma dada transação. A repetição (ou frequiência) de uma mesma espécie de transação, juntamente com o grau de risco envolvido, representa elementos relevantes para a escolha da estrutura de governança mais adequada para uso, em função de seu efeito no nível do custo de transação. Grandori e Soda (1995) apresentam contribuições sobre os mecanismos de coordenação e uma tipologia das redes interorganizacionais que são classificadas em três diferentes tipos: as redes socias, as burocráticas e as proprietárias.

As diferenças básicas, conforme sugerem Marsh e Rhodes (1992), não estão unicamente na forma de coordenação (grande empresa, organização supracadeias, etc.), mas nos tipos de interesses, na utilização e distribuição dos recursos de poder e na qualidade da integração (em termos de frequiência, continuidade e existência de conflito). Assim, existem recursos por parte de todos os participantes, quando os interesses são econômicos e profissionais, as relações são freqüentes e contínuas e não há o conflito porque os membros da rede participam e avaliam os resultados para legitimá-los. A rede torna-se mais fechada, pois é mais estável, institucionalizada e integrada. De modo contrário, quando existem vários tipos de interesses permeando as relações em rede, os contatos são mais flutuantes e certos atores apresentam poucos recursos, prevalecendo o resultado de soma zero na relação (um ganha e outro perde), a rede é instável, aberta, pouco institucionalizada e integrada.

\section{Apresentação da abordagem proposta}

Os participantes dentro da "rede física" desenvolvem e desempenham as atividades de entrega de fornecimentos e produtos entre firmas e clientes finais. Esta rede faz as coisas acontecerem, como levar fornecimentos e matériaprima dos fornecedores aos locais de produção, produzir fisicamente produtos e serviços, manipular materiais dentro das fábricas de produção, desempenhar atividades de estocagem e de entrega de produtos para clientes finais. Esses tipos de atividades devem ser considerados sob o cenário total envolvendo cada uma das firmas dentro da rede com o objetivo de manter o sistema produtivo funcionando (Tabela 1).

Os assuntos que podem impactar, direta ou indiretamente, o desempenho dos atores no âmbito de cada tipo de rede, foram considerados dentro do modelo e podem ser visualizados de forma resumida na Figura 1.

Para ilustrar a aplicabilidade do modelo ora proposto, com o objetivo de avaliar a competitividade de redes de operações, este artigo apresenta os resultados preliminares obtidos da análise feita para o aspecto "relacionamento com parceiros - alianças".

Delimitado o foco de trabalho, foi desenvolvida uma agenda de itens a serem abordados em entrevistas, que ocorreram de fato nas empresas parceiras. Os objetivos colocados para as entrevistas foram obter elementos que permitissem conhecer e compreender os mecanismos e procedimentos relevantes, considerando o assunto "aliança” e suas implicações em cada tipo específico de rede, conforme a dinâmica típica dos processos que ocorrem nos limites da rede de negócios; quais empresas estão presentes dentro da rede de negócios e quais atividades são por elas desenvolvidas; o mapeamento dos processos

\begin{tabular}{|c|c|c|c|c|c|c|c|c|c|c|}
\hline Sujeitos & \multicolumn{3}{|c|}{ Papéis de Fábricas } & \multicolumn{2}{|c|}{ Produção } & \multirow[b]{2}{*}{ Localização } & \multirow[b]{2}{*}{ Flexibilidade } & \multicolumn{2}{|c|}{ Parcerias } & \multirow{2}{*}{ Aliança } \\
\hline Rede & Estratégia & Tecnologia & \begin{tabular}{|c|} 
Projeto \\
Prod./Proc \\
\end{tabular} & \begin{tabular}{|c|} 
Tipos de \\
Processos
\end{tabular} & $\begin{array}{c}\text { Conhecimento } \\
\text { Operacional }\end{array}$ & & & Trust & Governança & \\
\hline $\begin{array}{l}\text { Física } \\
\text { Valor } \\
\text { Negócios }\end{array}$ & & & & & & & & & $\begin{array}{l}1 \\
\vdots \\
\vdots \\
\vdots \\
1\end{array}$ & \\
\hline
\end{tabular}

Figura 1. Modelo de redes simultâneas. 
Tabela 1. As redes, suas atividades e seus atores.

\begin{tabular}{|c|c|c|}
\hline Redes & Atividades ou funções & Atores \\
\hline Negócios & $\begin{array}{l}\text { - Aferir e medir as necessidades ditadas por um determi- } \\
\text { nado Mercado; } \\
\text { - Descobrir tais necessidades e repassar para os parceiros } \\
\text { de negócios; } \\
\text { - Desenvolver as atividades comerciais e negociais; } \\
\text { - Desenvolver e executar atividades para facilitar o } \\
\text { acesso de clientes a Produtos/Serviços (sob o ponto de } \\
\text { vista financeiro); } \\
\text { - Dar o input para as atividades de produção; e } \\
\text { - Determinar quem faz o que na rede global. }\end{array}$ & $\begin{array}{l}\text { - Representante comercial; } \\
\text { - Varejistas; } \\
\text { - Intermediários financeiros; } \\
\text { - Atacadistas; } \\
\text { - Empresas com suas áreas comerciais e de marketing; } \\
\text { - Empresas de pesquisa de mercado; } \\
\text { - Infomediários; e } \\
\text { - Seguradoras. }\end{array}$ \\
\hline Valor & $\begin{array}{l}\text { - Desenvolver alternativas para obtenção das condições } \\
\text { que permitem atender (via P/S) às necessidades que os } \\
\text { clientes consideram importantes; } \\
\text { - Determinar quem faz o que dentro da rede global; e } \\
\text { - Aferir e medir a obtenção dos valores definidos. }\end{array}$ & $\begin{array}{l}\text { - Empresas ou atores dentro da rede (física ou não); } \\
\text { - Empresas com suas áreas de projeto de produtos e servi- } \\
\text { ços e de processos; e } \\
\text { - Empresas ou atores ligados à obtenção de um determina- } \\
\text { do item de valor. }\end{array}$ \\
\hline Física & $\begin{array}{l}\text { - Viabilizar o atendimento físico (ou objetivo) das neces- } \\
\text { sidades definidas; } \\
\text { - Desenvolver alternativas para obtenção da condição } \\
\text { física (ou objetivo) das necessidades definidas; } \\
\text { - Determinar quem faz o que dentro da rede global; } \\
\text { - Aferir e medir a obtenção dos valores definidos; } \\
\text { - Fluxo físico de bens ou linhas de fluxo de serviço entre } \\
\text { os principais da rede de criação de valor e entre estes e } \\
\text { o mercado atendido; } \\
\text { - Aferir e medir variáveis de fluxo; e } \\
\text { - Atender a programa de pedidos. }\end{array}$ & $\begin{array}{l}\text { - Empresas que efetivamente produzem os bens e serviços } \\
\text { (físicos ou não) com os valores que se deseja para atendi- } \\
\text { mento de mercado; } \\
\text { - Empresas que transportam (fisicamente ou não) bens e } \\
\text { serviços entre atores; e } \\
\text { - Empresas que transportam (fisicamente ou não) a distri- } \\
\text { buição ao mercado. }\end{array}$ \\
\hline
\end{tabular}

críticos em função de sua importância relativa, ou de seu potencial de contribuição para a formação da competitividade da rede de negócios, bem como seus reflexos na rede de operação como um todo; a importância de se desenvolverem alianças entre os atores envolvidos na rede de negócios; como são operacionalizadas na prática as alianças estabelecidas; e como é feito o acompanhamento do desempenho destas alianças.

Complementando a análise, no que tange aos aspectos referentes às alianças entre atores da rede de operações, foi considerada a tipologia sugerida por Gattorna e Walters (1996), para mapeamento e avaliação do nível dos relacionamentos existentes, independente destes serem de caráter vertical ou horizontal, como propõe o autor.

O modelo de mapeamento descreve quatro níveis principais, nos quais podem ser classificados os relacionamentos existentes nas redes, considerando a importância das transações em sua origem e destino, para as operações de quem presta o serviço e de quem o recebe. $\mathrm{O}$ autor define os dois extremos de um relacionamento como sendo o lado "fornecedor" e "comprador" do objetivo ou atividade sendo desenvolvida (Figura 2).

Adotando o esquema de classificação sugerido por Gattorna e Walters 1996, pode-se ter uma idéia acerca da profundidade e abrangência adequada em nível de relacionamento entre os atores de um determinado relacionamento. A aliança resultante deve, portanto, ser mais estrategicamente tratada quanto menor for o nível do relacionamento existente. E uma vez feito o mapeamento da importância dos relacionamentos dentro das redes, considerando-se o status quo referente às alianças existentes, pode-se traçar um quadro com as avaliações correspondentes e eventuais desvios e as correções necessárias para reequilibrar a situação, em consonância com o que exige o contexto formado pelos objetivos dos envolvidos.

\section{0 setor de papel e celulose}

\subsection{A competição global}

Os negócios envolvendo papel e celulose representavam, ao final da década de 90, algo em torno de US\$ 90 bilhões, ou uma produção estimada de 27 milhões de toneladas (Bracelpa, 2004).

É importante relatar que a evolução ocorrida na qualidade produzida, elevou a produção física a outro patamar. Neste sentido, pode-se notar a elevação percentual da produção originada na América Latina. Do mesmo modo, é possível verificar quedas significativas na produção relativa aos países do leste Europeu e da América do Norte, abrindo espaço para os aumentos verificados nos outros países. No entanto, é nas condições ou pressupostos de competitividade que ocorreram as mudanças mais importantes. A evolução das questões correspondentes à 


\begin{tabular}{|c|c|l|}
\hline Nível & Fornecedor & Comprador \\
\hline 1 & Alto & Alto \\
2 & Alto & Baixo \\
3 & Baixo & Alto \\
4 & Baixo & Baixo \\
\hline
\end{tabular}

Figura 2. Mapeando as relações de dependência. Fonte: Gattorna e Walters (1996).

qualidade e à conservação do meio ambiente reforçou alguns fatores tradicionais como o preço de venda, elevando também a importância relativa de aspectos até pouco tempo considerados como secundários.

A dinâmica de uma globalização, que apresenta um centro de gravidade cada vez mais indistinto, baseado em blocos econômicos ao invés de países isolados, bem como o aparecimento de "novos" e significativos atores no cenário internacional de papel e celulose (como a China, por exemplo), também acarretou uma mudança de igual magnitude na forma de gerir as empresas, definir seus produtos e mercados. Assim, muitos movimentos de acomodação das empresas e países podem ser notados para a formação do contexto atual em que se desenvolvem os negócios. Aspectos ligados à qualidade e conservação do meio ambiente adquirem importância equivalente ao preço de venda. Os produtos celulose e papel continuam a ser considerados commodities, a despeito das exigências em qualidade e conservação ambiental, fazendo com que o preço seja um ganhador de pedidos (Hill, 2000). Empresas passam a perseguir objetivos ligados à certificação de Qualidade (Normas da Série ISO 9000 e ISO 14000) e conservação do meio ambiente (selo verde), com a mesma intensidade que perseguem objetivos ligados à produtividade. Fusões e aquisições passam a fazer parte da realidade do setor, em que o objetivo é obter margem de manobra, poder de barganha com fornecedores e níveis superiores de produtividade. Plantas passam a atuar de forma focalizada, dirigida a uma ou poucas linhas principais de produtos, objetivando atingir níveis de escala mais elevados e eficientes.

Órgãos de fomento do Governo passam a desempenhar um papel muito mais importante, tanto no financiamento às exportações como na aquisição de máquinas e equipamentos e implantação de novos projetos industriais. $\mathrm{O}$ estabelecimento de parcerias com institutos de pesquisa e universidades passa a ter um caráter praticamente mandatário, tendo em vista a evolução tecnológica de produtos e processos, inviabilizando a atuação de empresas isoladas neste quesito.

\subsection{A indústria brasileira de papel e celulo- se}

A indústria brasileira de papel e celulose representa hoje um importante segmento da economia. Seu desempenho e abrangência podem ser avaliados pelos dados básicos, ou seja, 220 empresas; 100 mil empregos diretos em fábricas e atividades de base florestais; US\$ 31 bilhões em exportações, gerando um saldo comercial de US\$ 2,5 bilhões; cerca de US\$ 570 milhões de impostos pagos; utilização exclusiva de madeira de florestas plantadas (eucalipto e pinus); 1,5 milhão de hectares de florestas plantados em 11 estados e $394 \mathrm{mu}-$ nicípios; 1,5 milhão de hectares de florestas nativas e preservadas; 3 milhões de toneladas de papel reciclados anualmente.

A produção nacional de celulose e papel coloca o Brasil em $7^{\circ}$ e $11^{\circ}$ respectivamente, no ranking mundial do setor, revelando não só a magnitude do segmento na economia do país, mas também o reflexo dos investimentos feitos pelas empresas em direção a patamares mais elevados de produção e produtividade. Novas plantas, maiores áreas reflorestadas, maiores investimentos em P\&D de novos produtos e processos, fusões e aquisições de empresas isoladas, trouxeram novo rigor competitivo aos conglomerados.

No mercado doméstico, a competição se tornou mais acirrada, no segmento de produtos de maior valor agregado, como papel de imprimir e escrever (I\&E) e embalagem, enquanto que no mercado internacional, as empresas brasileiras se tornaram mais aptas a competir principalmente no segmento de commodities (celulose). A conjugação de outros aspectos externos, como a repercussão das economias americana, européia e japonesa, além do crescimento da economia chinesa, ajuda a explicar esse movimento positivo. Como resultado da baixa volatidade dos preços externos da celulose e de papel de escrever, as empresas do setor foram praticamente induzidas a procurar com maior intensidade por mercados externos para diversificar e elevar o volume de vendas dos produtos.

Aliado a isso, outros fatores conjunturais, como elevadas taxas de juros adotadas pelo Banco Central do Brasil, contribuíram para a retração da demanda doméstica por papel. Ainda com boa aceitação e respondem, pouco a pouco, por significativa parcela de valores exportados pelo setor. No entanto, pode-se afirmar ainda, com relação aos resultados da equação chinesa, que os maciços investimentos feitos naquele país em novas plantas, principalmente produtoras de papel, o volume crescente de aquisição de celulose ao mercado internacional, idem no que diz respeito a aparas de papel, indicam a velocidade com que as coisas estão evoluindo. Com isso, pode-se prever que, em um futuro não muito distante, tendo suprido a demanda interna, considerando ainda o menor custo relativo dos fatores de produção chineses, a exportação dos excedentes deverá trazer preocupações adicionais aos atuais exportadores. 


\section{A empresa pesquisada}

\subsection{Descrição da empresa e sua relevância}

A Cia. Suzano de Papel e Celulose engloba atualmente diversas empresas e os resultados preliminares aqui apresentados referem-se apenas a uma de suas linhas de negócios, operacionada principalmente em sua planta localizada na cidade de Suzano (SP). A capacidade de produção de celulose é de 1,0 milhão de toneladas anuais, sendo 410 mil toneladas destinadas ao mercado (interno e exportação), e o restante utilizado na produção de papéis, cuja capacidade atual é de cerca de 775 mil toneladas/ano. Os principais produtos são: celulose de eucalipto, papel de I\&E não revestido e revestido (couché) e papel cartão. A capacidade plena de produção, após o término dos projetos de modernização em 2004, será de 1.290 mil toneladas/ano.

A base industrial da empresa é composta por três unidades industriais, sendo duas no Estado de São Paulo e outra em Mucuri, no Estado da Bahia. A base florestal própria é composta por 269,8 mil hectares de terra, próximas às plantas produtivas, sendo 164,9 destinadas ao plantio e o restante para preservação ambiental. Tem como linhas estratégicas, que norteiam as operações da empresa, a expansão e a modernização da produção; o desenvolvimento de novos produtos com maior valor agregado; o aumento da eficiência operacional; a melhoraria do relacionamento com instituições externas, bolsas de valores e empresas de financiamento; os aspectos sociais e de conservação ambiental; e a busca pela excelência em gestão.

A produção de celulose para a venda em 2003 foi de 424,9 mil toneladas e 776,4 mil toneladas de papéis em geral, perfazendo um total de 1201,3 mil toneladas, maior do que a capacidade nominal foi alcançada após implementação de melhorias operacionais que elevaram a eficiência do sistema produtivo. As vendas totais de 2003 foram de 1153,6 mil toneladas. Diante da retração da demanda do mercado doméstico de papéis, as vendas sofreram uma forte redução (469 mil/t em 2003 contra $539,5 \mathrm{mil} / \mathrm{t}$ em 2002). No entanto, a conjuntura global positiva do mercado internacional permitiu à empresa redirecionar grande parte do volume de vendas para exportação. Em volume, as exportações de 2003 cresceram em torno de $10 \%$ num total de $684,5 \mathrm{mil} / \mathrm{t}$., respondendo por $59,3 \%$ do volume total vendido, em comparação com $53,6 \%$ em 2002, crescimento obtido de forma diversificada, atendendo clientes de 77 países. A receita líquida de vendas alcançou US\$ 855 milhões em 2003, um aumento de $19,8 \%$ em relação a 2002.

Segundo Bracelpa (2004), os destinos das vendas em geral (em volume), de todas as exportações realizadas em 2003, foram a Ásia (21,9\%), Europa (35,7\%), América do Norte $(18,5 \%)$ e outros $(24,0 \%)$.

Considerando o negócio "papel", a Tabela 2 mostra a evolução das vendas (em volume).

Observando-se as receitas de vendas, os dados sugerem que, ao longo do período, ocorreu uma evolução positiva dos volumes exportados de papéis, demonstrando claramente a opção da empresa em disputar o mercado externo. O direcionamento das vendas externas de produtos feitos de papel (em volume), ocorridas em 2003, foi a Ásia (12,5\%), Europa (25,6\%), América do Norte $(12,4 \%)$, América $(31,9 \%)$ e outros $(17,7 \%)$.

\subsection{0 sistema de operações}

\subsubsection{Configuração básica do processo produtivo}

Os processos produtivos configuram-se como de produção contínua, utilizando equipamentos de grande porte, linhas dedicadas e com elevado grau de automoção, o que permite classificá-lo como capital-intensivo. A base florestal, no entanto, apesar de empregar equipamentos de última geração, ainda responde por elevado número de empregos gerados, podendo ser classificada como mãode-obra intensiva.

\subsubsection{As redes simultâneas envolvidas}

O sistema de operações aqui tratado exibe um elevado grau de integração financeira, ou da propriedade dos fatores, bem como elevada integração organizacional, pois a maioria das decisões nas redes são tomadas de forma centralizada pela empresa produtora de papéis. Trata-se, portanto, de uma CS integrada (Morvan,1988), possuindo poucos elos físicos externos. Talvez como um reflexo do que acontece na rede física, na qual tem maior poder, a empresa produtora de papéis persegue continuamente a posição de máxima relevância também na rede de negócios. Neste caso, é mais difícil fazê-lo, porque os outros atores se relacionam com outras redes de operações, muitas vezes em outros países (por exemplo, trading companies) e apresentam um grau menor de exposição a esse tipo de pressão. Tal dependência, ou perda de poder, por parte da empresa produtora de papéis também vem ocor-

Tabela 2. Venda de produtos feitos de papel.

\begin{tabular}{cccc}
\hline Ano & $\begin{array}{c}\text { Venda } \\
(\mathbf{T})\end{array}$ & $\begin{array}{c}\text { Mercado Interno } \\
(\boldsymbol{\%})\end{array}$ & $\begin{array}{c}\text { Exportações } \\
(\boldsymbol{\%})\end{array}$ \\
\hline 1999 & 731.211 & 59 & 41 \\
2000 & 714.923 & 68 & 32 \\
2001 & 732.911 & 68 & 32 \\
2002 & 750.954 & 62 & 38 \\
2003 & 749.259 & 56 & 44 \\
\hline
\end{tabular}

Fonte: Bracelpa (2003) 
rendo na rede de valor, em função do papel cada vez mais importante desempenhado por outros parceiros presentes na rede. Podem-se citar as universidades e institutos de pesquisa em biotecnologia, cujos trabalhos vêm crescendo de importância na definição da competitividade dos produtos e serviços em um contexto concorrencial cada vez mais ávido por qualidade e inovação. Ainda que a celulose em si continue sendo uma commodity, seus processos, grau de homogeneidade e pureza, continuam sendo objetos de exigências crescentes na busca por melhorias. Fato que é mais fácil de ser explicado na linha de I\&E, mais sujeita as variações, customizações e evolução tecnológica.

O domínio da tecnologia de projeto de processos e de produtos vai migrando, pouco a pouco, das mãos das empresas produtoras, analogamente ao que tem ocorrido com a indústria automobilística, para os institutos de pesquisa e universidades, fortalecendo a sua posição relativa nas redes de valor de que participam. Assim, em função da posição relativa dos atores dentro das três redes aqui propostas pelo modelo, é que devem ser considerados e avaliados os tipos de alianças atualmente existentes. As questões de controle, coordenação e competição são tratadas em nível interno à rede de operações como um todo, sem representar problemas para a rede física.

Utilizando a classificação sugerida por North (1990), as redes não apresentam indícios de serem difusas, porque existem regras bem estabelecidas pela empresa produtora de papéis (centro de gravidade de poder da rede de operações total), dirigindo ou estabelecendo diretrizes para reconhecer os relacionamentos entre os atores. Tais regras podem ser formais, como as estabelecidas mediante contratos detalhados, ou informais (tacitamente escolhidas) e plenamente aceitas pelos demais atores presentes. Para estabelecimento do contexto analítico a ser utilizado no presente artigo, o modelo proposto representa um composto, ou uma rede de operações, formado pelas redes física, de valor e de negócios, bem como a unidade de negócio representada pelo item "papel I\&E". Com isso, podem-se definir as redes e obter a Tabela 3,

Tabela 3. Atores e atividades das redes física, de valor e de negócios.

\begin{tabular}{|c|c|c|}
\hline & Atores & Atividades \\
\hline \multirow{7}{*}{ 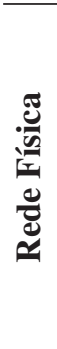 } & Floresta Suzano & Relativas ao processo de produção da base florestal, do plantio até a produção de madeira. \\
\hline & Floresta terceirizada & $\begin{array}{l}\text { Atividades iguais às desenvolvidas pela Suzano, com estreita supervisão e assistência especial (tecnoló- } \\
\text { gica e operacional) e um tipo de contrato detalhado com condições especiais de fornecimentos. }\end{array}$ \\
\hline & Firmas químicas & Relativas a fornecimentos de materiais químicos especiais a serem usados pelo processo de transformação. \\
\hline & Firmas de transporte & Transporte de madeira, fornecimentos químicos, produtos acabados e poluentes industriais. \\
\hline & Atacadistas & Armazenamento e distribuição de produtos finais e consumidores. \\
\hline & Varejistas & Admissão e armazenamento de produtos finais e entrega aos consumidores finais. \\
\hline & Ind. transformação & Produção física de celulose e papel. \\
\hline \multirow{5}{*}{ 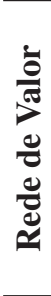 } & Floresta Suzano & Desenvolvimento de tecnologia de plantio e de biotecnologias e novas espécies. \\
\hline & Universidades & P\&D em biotecnologia para melhorar as espécies e os processos de produção. \\
\hline & Firmas químicas & P\&D para melhorar a qualidade de matérias-primas usadas no processo de transformação. \\
\hline & $\begin{array}{l}\text { Indústria de } \\
\text { transformação }\end{array}$ & P\&D para melhorar processos, produtividade, práticas de proteção ambiental e certificação de qualidade. \\
\hline & $\begin{array}{l}\text { Atacadistas e } \\
\text { varejistas }\end{array}$ & $\begin{array}{l}\text { Monitoramento das necessidades do consumidor e sua interação com a empresa a fim de melhorar } \\
\text { produtos e serviços. }\end{array}$ \\
\hline \multirow{6}{*}{ 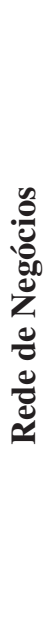 } & Suzano & $\begin{array}{l}\text { Monitoramento de mercados e definição de objetivos e metas a alcançar; obtenção e repasse de informa- } \\
\text { ções de negócios e oportunidades aos parceiros; realização de negócios e atividades comerciais típicos; } \\
\text { desenvolvimento de relações com parceiros potenciais ou empresas financeiras e de relações com ban- } \\
\text { cos de investimentos para implementação de novos projetos produtivos. }\end{array}$ \\
\hline & Atacadistas & $\begin{array}{l}\text { Desenvolvimento de estruturas apropriadas para servir o mercado, de relações com varejistas e consu- } \\
\text { midores finais, de relações com empresas de transporte a fim de obter melhores condições de acesso; } \\
\text { realização de negócios e atividades comerciais típicos. }\end{array}$ \\
\hline & Varejistas & $\begin{array}{l}\text { Criação de possibilidades de desenvolvimento de atividades de comércio em regiões ou cidades especí- } \\
\text { ficas e realização de atividades comerciais típicas. }\end{array}$ \\
\hline & Empresas financeiras & Desenvolvimento de linhas de crédito adequadas para dar suporte a atividades comerciais. \\
\hline & $\begin{array}{l}\text { Bancos de } \\
\text { investimentos }\end{array}$ & $\begin{array}{l}\text { Desenvolvimento de linhas de crédito para implementação de novos projetos produtivos e para dar } \\
\text { suporte às exportações da empresa. }\end{array}$ \\
\hline & Empresas comerciais & $\begin{array}{l}\text { Estudos do potencial de vendas do mercado; desenvolvimento de novos mercados; realização de } \\
\text { atividades específicas que possibilitem as exportações da empresa, de negócios e atividades comerciais } \\
\text { típicos; preparativos para fornecer documentação e atender às necessidades burocráticas do negócio em } \\
\text { atividade. }\end{array}$ \\
\hline
\end{tabular}


que mostra os atores envolvidos e as atividades desempenhadas no âmbito de cada uma delas.

\section{Informações preliminares e discussão}

Os dados e informações obtidas, mediante condução de entrevistas conduzidas junto a seus representantes funcionais, com base em uma agenda de assuntos pertinentes à unidade de negócios "papéis de I\&E", compõem as redes física, de valor e de negócios, envolvendo aspectos típicos do item "relacionamento com fornecedores". Com relação às redes física, de valor e de negócios que juntas formam a rede de operações total, foram feitos os levantamentos correspondentes aos relacionamentos atualmente existentes entre seus participantes, resultando no perfil apresentado pela Tabela 4.

\subsection{A rede física}

Os relacionamentos de nível 1 sugerem a necessidade de estratégias comuns e alinhadas com os interesses dos clientes finais dos sistemas de operações, ou seja, dos usuários finais dos papéis de I\&E, que correspondem ao foco da análise. Pode-se perceber que a iniciativa das ações, na rede física, está nas mãos da empresa produtora. O mesmo nível de relacionamento com sua base florestal não impede que a empresa produtora exerça

Tabela 4. Mapeamento dos relacionamentos.

\begin{tabular}{|c|c|c|c|}
\hline Relacionamentos & Física & Valor & Negócios \\
\hline $\begin{array}{l}\text { Floresta de Suzano - Fábrica de } \\
\text { Suzano }\end{array}$ & 1 & 1 & - \\
\hline $\begin{array}{l}\text { Floresta terceirizada - Fábrica de } \\
\text { Suzano }\end{array}$ & 2 & - & - \\
\hline $\begin{array}{l}\text { Mão-de-obra terceirizada - Fábrica } \\
\text { de Suzano }\end{array}$ & 2 & - & - \\
\hline $\begin{array}{l}\text { Firmas químicas - Fábrica de } \\
\text { Suzano }\end{array}$ & 3 & 1 & - \\
\hline $\begin{array}{l}\text { Firmas de transporte - Fábrica de } \\
\text { Suzano }\end{array}$ & 2 & - & - \\
\hline $\begin{array}{l}\text { Atacadistas específicos - Fábrica } \\
\text { de Suzano }\end{array}$ & 2 & 4 & 1 \\
\hline $\begin{array}{l}\text { Atacadistas genéricos - Fábrica de } \\
\text { Suzano }\end{array}$ & 4 & 4 & 3 \\
\hline Varejistas - Fábrica de Suzano & 4 & 4 & 3 \\
\hline $\begin{array}{l}\text { Floresta de Suzano - Floresta } \\
\text { terceirizada }\end{array}$ & - & 2 & - \\
\hline Universidade - Fábrica de Suzano & - & 1 & - \\
\hline Universidade - Floresta de Suzano & - & 1 & - \\
\hline $\begin{array}{l}\text { Empresas financeiras - Fábrica de } \\
\text { Suzano }\end{array}$ & - & - & 1 \\
\hline $\begin{array}{l}\text { Bancos de investimentos - Fábrica } \\
\text { de Suzano }\end{array}$ & - & - & 1 \\
\hline $\begin{array}{l}\text { Empresas comerciais - Fábrica de } \\
\text { Suzano }\end{array}$ & - & - & 1 \\
\hline
\end{tabular}

Fonte: Adaptado de Gattorna e Walters, 1996 seu poder, ditando as normas de relacionamento entre processos, em função da centralização da coordenação necessária a um processo produtivo bastante verticalizado. Alguns relacionamentos, apesar de não serem muito importantes para a competição, podem alterar o quadro para pior, caso o parceiro da rede não eleve sua importância de relacionamento com a produtora de papel e, ainda que a situação não seja muito difícil no que tange ao relacionamento com distribuidores genéricos de seus produtos e com varejista, a empresa produtora poderia aumentar o seu peso relativo nas operações desses parceiros por meio de incentivos, prêmios de vendas e outras providências. Adicionalmente, contratos de prazo mais longo para fornecimentos de insumos de base química poderiam atenuar um pouco o desequilíbrio de interesses no relacionamento, atualmente favorável aos fornecedores.

\subsection{A rede de valor}

Os relacionamentos de nível 1 ocorrem principalmente com parceiros externos e fora do alcance de controle da empresa produtora, como as universidades voltadas a $\mathrm{P} \& \mathrm{D}$ de produtos e processos da base florestal, com seus instrumentos de formalização, estabelecendo vínculos entre os programas de pesquisas e a empresa, havendo uma interação significativa entre as partes. Contudo, os relacionamentos nível $1 \mathrm{com}$ fornecedores de insumos químicos refletem algum desbalanceamento em relação ao que ocorre na rede física. Assim, poder-se-ia estudar a adoção de alguma medida para equilibrar o conjunto das relações em todas as redes, por exemplo, mediante uma maior concentração das aquisições em alguns poucos fornecedores, ou ainda estabelecendo algum tipo de bônus, determinado em função da performance dos produtos no mercado. Quanto ao restante dos relacionamentos na rede de valor, nota-se um certo equilíbrio de interesses se for considerado apenas o conjunto com a rede física. Contudo, alguns desvios potencialmente importantes podem ser considerados em conjunto com os relacionamentos com a rede de negócios.

\subsection{A rede de negócios}

Os relacionamentos de nível 1 detectados sugerem a necessidade da empresa produtora trabalhar formas de relacionamentos mais profundas com seus parceiros, principalmente nos relacionamentos envolvendo empresas financeiras, bancos de investimentos e trading companies, que atendem muitos outros parceiros de outras redes de operações. Assim, a empresa produtora poderia adotar mecanismos de alinhamento estratégico para correção dos desvios, adotando-se uma maior participação nas empresas parceiras visando garantir condições de atendimento preferencial. Outra alternativa poderia ser a extensão dos contratos por um período mais longo. 
Da mesma forma, torna-se importante a disponibilidade de sistemas de informações integradas, como um fator de melhoria de desempenho nas atividades que exigem uma atuação conjunta ou integrada. Outro relacionamento nível 1 existente entre a empresa produtora e seus distribuidores específicos, não apresenta desequilíbrio, considerando o conjunto das três redes simultâneas. No entanto, o mesmo não se pode dizer quanto aos relacionamentos "genéricos". Neste caso, a empresa produtora poderia trabalhar no desenvolvimento de processos comerciais mais rápidos e fáceis de acessar do que seus concorrentes, estimulando nos parceiros a transparência e fluidez das informações e agilizando as condições de fechamento de contratos. Assim, implementando condições de relacionamento mais atrativas, poder-se-ia esperar uma elevação das vendas por intermédio destes relacionamentos, elevando o grau de dependência dos parceiros envolvidos. O resultado final poderia ser encarado como sendo a tendência a uma posição de maior equilíbrio, considerando-se o conjunto das três redes simultâneas.

\section{Conclusões}

O estudo parte de uma pesquisa mais abrangente ainda em desenvolvimento, apresenta uma forma alternativa para avaliação da competitividade de redes de empresas, segmentando a rede de operações total em sub-redes, envolvendo atividades e relacionamentos físicos, de formação de valor e da comercialização e desenvolvimento de negócios. A pesquisa de campo realizada, e apresentada em caráter preliminar, foi feita utilizando o modelo proposto, envolvendo aspectos correspondentes apenas às alianças entre os atores nas redes identificadas e fazendo uso de um contexto de mapeamento de relacionamentos sugerido por Gattorna e Walters (1996). Os resultados preliminares apresentados permitem visualizar o potencial analítico do modelo, revelando aspectos não só típicos de cada rede, mas da inter-relação que deve haver entre as redes simultâneas. O objetivo é apontar caminhos que permitam atingir um nível de equilíbrio, balanceado, com as exigências características do tipo de operação analisado e do contexto concorrencial em que se insere nas operações analisadas. A conclusão final é que o modelo apresentado, assim como muitos outros, não é bastante suficiente para uma análise completa, mas representa uma forma alternativa que, em conjunto com outros modelos adequados a cada tipo de assunto focalizado, pode trazer informações vitais para uma condução estrategicamente equilibrada das operações.

\section{Referências Bibliográficas}

BENKO, G. Economia, espaço e globalização na autora do século XXI. São Paulo: HUCITEC, 1996.

BOWMAN, C.; AMBROSINI, V. Value creation versus value capture: towards a coherent definition of value in strategy, British Journal of Management, v. 11, p. 1-15, 2000.

BOYSON, S.; et al. Logistics and the extended enterprise. New York: John Wiley \& Sons, 1999.

BRACELPA. Associação Brasileira de Celulose e Papel. Disponível em: <http://bracelpa.com.br>. Acesso em: 15 março 2004.

CHRISTOPHER, M. Logistics and Supply Chain Management: strategies for reducing costs and improving services. London: Pitman Publishing, 1992.

COMPANHIA SUZANO DE PAPEL E CELULOSE. Disponível em <http://www.suzano.com.br>. Acesso em: 15 março 2004.

CORRÊA, H. L. Contribution for the understanding of the history of operations management, EurOMA-POMS CONFERENCE, 2003, Como, Italy. Proceedings... p. 891-898, 2003.

FERDOWS, K. Making the most of foreign factories. Harvard Business Review, March-April, p. 73-88, 1997.
FUSCO, J. P.; SPRING, M. Flexibility versus robust networks: the case of the Brazilian automotive sector. Integrated Manufacturing Systems, v. 14, n. 1, p. 26-35, 2003.

GRANDORI, A.; SODA, G. Inter-firm networks: antecedents. Mechanisms and forms. Organization Studies, v. 16, n. 2, p. 183-214, 1995.

GATTORNA, J.; WALTERS, D. W. Managing the supply chain: a strategic perspective. London: Macmillan Press, 1996.

GULATI, R. Network location and learning: the influence of network resources and firm capabilities on alliance formation. Strategic Management Journal, n. 20, p. 397-420. 1999.

HILL, T. Process positioning. In: Manufacturing strategy: the strategic management of the manufacturing function. London: Macmillan, 2000. p. 184-270.

HINES, P.; et al. Value Stream Management. London: Pearson Education Limited, 2000.

JARILLO, J. C. Strategic networks: creating the borderless organization. Oxford: Butterword-Heinemann, 1998.

LE GALÈS, P. Les réseaux dáction publique entre outil passe-partout et théorie de moyene portée. In: LES GALÈS, 
P.; THATCHER, M. (orgs). Le réseaux de politique publique. debaut autor des policy networks. Paris: L' Harmattan, p. 14-28, 1995.

MARSH, J. G.; OLSEN, J. P. El Nuevo institucionalismo: factores organizativos de la vida política. Madrid: $\mathrm{Pa}$ blo Iglesias, Zona Abierta, v. 63, n. 63, p. 1-43, 1993.

MARSH, D.; RHODES, R. A. Policy networks in British politics. A critique of existing approaches. In: RHODES, R.A.; MARSH, D. Policy networks in British government. Oxford: Clarendon Press, 1992. p.1-26.

MORVAN, Y. Fundamentos de economia industrial. Paris: Economica, 1988.

NOOTEBOOM, B. Inter-firm alliances: analysis and design. London: Routledge, 1999.

NORTH, D. C. Institutions, institutional change and economic performance. New York: Cambridge University Press, 1990.

PAROLINI, C. The value net: a tool for competitive strategy. Chichester: John Wiley \& Sons, 1999.

PAULILLO, L. F. Redes de poder \& territórios produtivos: indústria, citricultura e políticas públicas no Brasil do século XX. São Carlos: UFSCAR, 2000.

POIRIER, C. C.; REITER, S. E. Supply Chain Optimization: building the strongest total business network. San Francisco: Berrett-Koehler Publishers, 1996.

PORTER, M. Competitive Advantage: creating and sustaining superior performance. New York: Free Press, 1985.

PRAHALAD, C. K.; HAMMEL, G. The core competence of the Corporation. Harvard Business Review, p. 79-91, 1990.
SACOMANO NETO, M. Redes, difusão de conhecimento e controle: um estudo de caso da indústria brasileira de caminhões. Tese (doutorado). Universidade Federal de São Carlos, São Carlos, 2004.

SAUNDERS, M. Strategic purchasing \& supply chain management. London: Pitman Publishing, 1997.

SCHMENNER, R. W. Look beyond the obvious in plant location. Harvard Business Review, May-June, p. 126-132, 1979.

SLACK, N., CHAMBERS, S. HARLAND, C. Operations Management. 2 ed., London: Pitman Publishing, 1998.

SPEKMAN, R. et. al. An empirical investigations into Supply Chain management: a perspective on partnerships, International Journal of Physical Distribution \& Logístics Management, v. 28, n. 8, p. 630-650, 1998.

VAN WAARDEN, F. Dimensions and types of policy networks. European Journal of Political Research, 1992, v. 21, p.29-52.

VOLlmanN, T. E., CORDON, C. Supply Chain Management, Business Briefing: Manufacturing 2000 Forum, n. 8, Summer, Lausanne, IMD, 1996.

VOLLMAnN, T. E., CORDON, C., RAABE, H. Supply Chain Management: making the virtual organization work. Executive Report: Manufacturing, n. 19, February, Lausanne, IMD, 1996.

WILLIAMSON, O. The economic institutions of capitalism. New York: Free Press. 1985.

WILLIAMSON, O. The nature of the firm: origins, evolution, and development. Oxford: Oxford University Press, 1991.

\title{
CONCURRENT NETWORKS MODEL FOR THE EVALUATION OF COMPANY NETWORK COMPETITIVENESS
}

\begin{abstract}
Network formation and development and the SCM theory have gained ground in recent years. Over time, Operations Management has evolved to embrace a more holistic perspective, and today encompasses issues such as supply networks, governance, relationships of trust, and others. Along the same lines, researchers have contributed much, primarily insofar as aspects of competitiveness are concerned, producing a wide variety of assessment models and typologies. However, the general purpose has been to explain the dynamics of a business and how a company's competitive guidelines must change to ensure success. This paper proposes an alternative methodological approach based on three main dimensions of concurrent networks, i.e., the physical, value and business network, to underpin the overall assessment of networks and supply chain competitiveness. The paper also discusses some preliminary findings and information taken from an ongoing survey of pulp and paper industry networks, which involves the use of the proposed model.
\end{abstract}

Keywords: networks, supply chain, concurrent networks, assessment model. 